\title{
DECIFRANDO O "MISTÉRIO DOS GÊMEOS": VINTE ANOS DE PESQUISA EM CÂNDIDO GODÓI, RIO GRANDE DO SUL
}

\author{
SOLVING THE "TWINS MYSTERY": TWENTY YEARS \\ OF RESEARCH IN CÂNDIDO GODÓI, RIO GRANDE \\ DO SUL STATE
}

\author{
Ursula Matte ${ }^{1,2}$, Augusto César Cardoso-dos-Santos ${ }^{2}$, \\ Graziella Rodrigues ${ }^{1}$, Marcelo Zagonel de Oliveira3 ${ }^{3}$, Alice Tagliani-Ribeiro², \\ Selia Heck ${ }^{4}$, Vanusa Dresch ${ }^{4}$, Merci Schossler ${ }^{4}$, Lavínia Schuler-Faccini ${ }^{1,2}$
}

\section{RESUMO}

Cândido Godói (CG) é um pequeno município brasileiro localizado no noroeste do Rio Grande do Sul e é conhecido como "Cidade dos Gêmeos" devido à alta taxa de nascimentos gemelares na região. Diante de um fato tão notável, muitas explicações foram sugeridas. Entre estas teorias, a que mais recebeu atenção da mídia, mesmo sem base científica, foi a de que a gemelaridade seria fruto de experimentos de um médico nazista alemão foragido após a Segunda Guerra Mundial. A convite da própria comunidade de CG, nosso grupo de pesquisa trabalha para resolver este mistério desde 1994, analisando diferentes fatores possivelmente relacionados, em especial suas características genéticas. Aqui, nós sumarizamos os principais resultados obtidos em mais de duas décadas de pesquisa, com foco nas particularidades do processo de comunicação dos resultados, aspectos éticos e como os achados científicos naquela comunidade contribuem não apenas com a resolução de um mistério histórico e local, mas também com o estudo de outras questões, como a reprodução humana e as bases biológicas da gemelaridade.

Palavras-chave: INaGeMP; gêmeos; efeito fundador; isolamento reprodutivo; fertilidade; genética médica populacional

\begin{abstract}
Cândido Godói (CG) is a small town located in the northwest region of Rio Grande do Sul state which is known as "Town of Twins" because of the high rate of twin births. Many explanations have been suggested for such a noteworthy fact. The theory that has received most attention from the press, despite a lack of scientific evidence, was that twinning would result from experiments conducted by a Nazi German physician who had been a fugitive after World War II. Invited by the local community, our research team has been dedicated to solving this mystery since 1994 by analyzing different possibly related factors, especially genetic characteristics. In this paper, we summarize the main results obtained in more than two decades of research, focusing on the particular communication process of the results, ethical aspects, and how the scientific findings in that community have contributed not only to the resolution of a historical and localized mystery, but also with the study of other issues such as human reproduction and biological basis of the twinning process.
\end{abstract}

Keywords: INaGeMP; twins; founder effect; reproductive isolation; fertility; population medical genetics

A Genética Médica Populacional visa o estudo e o cuidado médico da população, e não do indivíduo ou da família, como é a prática normal genética clínica ou médica ${ }^{1,2}$. Com base nessa premissa, o Instituto Nacional de Ciência e Tecnologia de Genética Médica Populacional (INaGeMP) foi criado em 2008,
Clin Biomed Res. 2019;39(2):107-115

1 Serviço de Genética Médica Populacional (INAGEMP), Hospital de Clínicas de Porto Alegre (HCPA). Porto Alegre, RS, Brasil.

2 Departamento de Genética, Serviço de Genética Médica Populacional (INAGEMP), Universidade Federal do Rio Grande do Sul (UFRGS). Porto Alegre, RS, Brasil.

3 Laboratório de Sensoriamento Remoto e Cartografia Digital (LASERCA), Serviço de Genética Médica Populacional (INAGEMP), Universidade do Vale do Rio dos Sinos (UNISINOS). São Leopoldo, RS, Brasil.

4 Prefeitura Municipal de Cândido Godói. Cândido Godói, RS, Brasil.

Autor correspondente: Lavínia Schuler-Faccini Ischuler@hcpa.edu.br Universidade Federal do Rio Grande do Sul (UFRGS)

Av. Bento Gonçalves, 9500. Caixa Postal 15053, 91501-970, Porto Alegre, RS, Brasil. 
tendo como sede o Serviço de Genética Médica do Hospital de Clínicas de Porto Alegre (SGM-HCPA) ${ }^{3}$.

Geralmente, a Genética Médica Populacional é aplicada quando alguma comunidade apresenta alta prevalência ou manutenção de doenças que são incomuns na população em geral ${ }^{2}$. Porém, fenótipos não necessariamente patológicos também podem surgir como resultado de eventos genéticos ligados à fundação de determinadas populações, como é o caso de uma pequena comunidade no sul do Brasil chamada Cândido Godói (CG), notável por apresentar altas taxas de nascimentos gemelares.

Localizado no noroeste do Rio Grande do Sul, quase no limite com a Argentina, o município conta com população pequena: 6535 habitantes ${ }^{4}$ com uma alta porcentagem $(74,2 \%$ e $98,2 \%$, conforme o distrito) da população descendente de ancestralidade alemã, decorrentes dos movimentos migratórios ocorridos no final do século 19 e inicio do século 20. De acordo com dados do Datasus do Ministério da Saúde do Brasil ${ }^{5}$, CG apresenta taxa média de nascimentos gemelares maior que a média nacional, ficando acima de $2 \%$. Particularmente, um distrito do município conhecido como Linha São Pedro apresenta prevalências de até $10 \%$ de gemelaridade . $^{6}$

Além de ser cientificamente interessante, este fenômeno foi relacionado, sem nenhuma base científica, a experimentações nazistas ligadas à passagem do médico Joseph Mengele pela América do Sul após o fim da Segunda Guerra Mundial ${ }^{7,8}$. Esta suposição, em parte, se deu pelo fato de que CG é composto principalmente por famílias de ancestralidade germânica. Estudando este fenômeno a pedido da própria comunidade, nosso grupo de pesquisa contribuiu com o entendimento da alta taxa gemelar em CG desde 1994, quando foi estabelecido o primeiro contato.

Neste artigo, descrevemos as pesquisas e estratégias para trabalhar com a população de CG para alcançar seu objetivo principal: elucidar o "mistério" da causa da alta taxa gemelar. Nosso objetivo neste artigo é mostrar o processo de comunicação com a comunidade, os aspectos éticos relacionados e os passos envolvidos na implantação de um processo de informação sobre as características genéticas de uma população.

\section{UM POUCO DE HISTÓRIA: A COLONIZAÇÃO ALEMÃ NO RS E AS ORIGENS DE CANDIDO GODÓI}

O início da imigração alemã no estado do Rio Grande do Sul inicia em 1824 quando o governo imperial cria a colônia de São Leopoldo. Já no período da República, a partir de 1889 até 1914, o governo do estado, agora responsável pela imigração, estabelece estatutos e impulsiona novas colônias na região do planalto. Os processos migratórios no Brasil ocorreram de maneiras distintas. No centro do Brasil (São Paulo), os imigrantes substituíram o trabalho escravo nos cafezais. Já no sul do país, tornaram-se proprietários de terras desde logo sua chegada ao Brasil $^{9-11}$.

Entre o fim do século XIX e inicio do século XX, estabeleceram-se colônias na região noroeste do estado do Rio Grande do Sul que reuniam imigrantes europeus, especialmente alemães e praticantes da religião católica. Estas colônias, classificadas como de características étnico-confessionais, foram incentivadas pelas autoridades do governo brasileiro e organizadas pela iniciativa privada, onde cada empreendimento tinha um sistema de organização própria. Geralmente reuniam indivíduos da mesma região geográfica do país de origem e mesma religião. A partir de 1914 muda o panorama da imigração, uma vez que Brasil e Alemanha ficam em lados opostos durante as duas guerras mundiais ${ }^{9,10}$.

No início do século $X X$, devido principalmente ao superpovoamento e esgotamento das terras das primeiras colônias do estado, houve migração interna para regiões mais distantes e menos povoadas, como o noroeste do Rio Grande do Sul ${ }^{9}$. Em 1902, a recém-fundada Associação de Novos Colonos (Bauerverein) compra terras na região das atuais cidades de Cerro Largo, Santo Cristo e CG. Essa região, portanto, é formada por migrantes descendentes dos primeiros colonizadores que se expandem da zona de colonização a partir da região do Vale dos Sinos e adjacências ("colônia velha") para o Noroeste do estado ("colônia nova").

\section{O PRIMEIRO CONTATO}

Em 1994, o SGM-HCPA foi contatado por um vereador de CG noticiando que os moradores locais notaram o fato de que muitas famílias tinham gêmeos. Também foi mencionado o trabalho de um jornalista argentino chamado Jorge Camarasa, o qual estava investigando a alegação de que Joseph Mengele havia visitado CG e estaria "envolvido" no nascimento de gêmeos ${ }^{8}$. A pedido do vereador por "uma investigação científica" para a ocorrência de gêmeos em CG, uma estudante de graduação (Ursula Matte) sob supervisão de Roberto Giugliani foi enviada à cidade de CG para entrevistar famílias, construir heredogramas e coletar sangue para estudos futuros.

Em seu trabalho, ela visitou a comunidade e entrevistou famílias com o maior número de gêmeos, que haviam sido previamente contatadas pelo vereador local. Os núcleos familiares localizavam-se em locais isolados e de difícil acesso, mas as famílias eram acolhedoras e colaborativas. Em uma segunda visita, 
gêmeos e familiares dispostos doaram sangue para análise molecular.

Assim como outras pequenas cidades do sul do Brasil, CG apresenta uma região central de maior densidade populacional circundada por diversas "linhas" (ou distritos) que se espraiam para o interior do município. De acordo com os primeiros resultados da investigação científica, notou-se que os nascimentos gemelares em CG concentravam-se em famílias e locais específicos da cidade, especialmente em um local conhecido como Linha São Pedro (LSP). Neste local, a taxa de nascimentos gemelares era de $10 \%$ para o período de 1990 a 1994, enquanto que a taxa brasileira para o mesmo período era estimada em $1.8 \%{ }^{6}$.

Na década de 1990, 84 famílias viviam no local, com uma população geral de 349 indivíduos, sendo 44 gêmeos. Amostras de sangue foram obtidas de 17 pares de gêmeos. Devido a dificuldades técnicas e ao custo para a realização de estudos genômicos à época, a análise de microssatélites foi utilizada para para determinar a zigosidade em gêmeos do mesmo sexo e investigar o papel de possíveis genes envolvidos na gemelaridade. Porém, a análise de treze marcadores no DNA, usando a técnica de Southern blot, não mostrou associação clara com a gemelaridade. Estudos de zigosidade sugeriram que a taxa de nascimento de ambos os gêmeos monozigóticos e dizigóticos era aumentada na região ${ }^{6}$.

Após o estudo, foi realizada uma reunião com a comunidade no pátio da escola local. Os resultados foram apresentados para as famílias participantes de maneira clara e acessível. Duas cópias do estudo foram deixadas para elas, uma permaneceu na biblioteca da escola e a outra foi posteriormente exibida no "Museu dos Gêmeos". Os investigadores (Matte e Giugliani) retornaram aos seus temas habituais de estudo. A vida continuou...

\section{RETORNANDO A CG}

Em 2008, mais de dez anos após a publicação do seu primeiro livro, Camarasa publicou um segundo livro sobre o assunto, desta vez ainda mais enfático em suas afirmações associando a alta frequência de nascimentos de gêmeos em CG com as experimentações nazistas de Joseph Mengele $^{7}$. Ele, inclusive, cita como evidência para sua teoria o trabalho de Matte et al. ${ }^{6}$, devido à ausência de uma causa genética definida para o fenômeno. De acordo com Camarasa, Mengele poderia ter vivido em CG no início dos anos 1960, apesar de suas suposições não se basearem em registros históricos reais disponíveis. As veementes alegações de Camarasa despertaram a atenção da mídia nacional e internacional, impressa e eletrônica, colocando a comunidade de CG, mais uma vez, em um dilema pois, se a teoria do jornalista argentino estivesse correta só haveria duas opções possíveis para os moradores: ou eles foram colaboradores dos experimentos nazistas ou eles foram vítimas inconscientes de uma pesquisa nada científica. Uma lista com algumas reportagens que noticiaram este fenômeno desde então é apresentada na Tabela 1.

Tabela 1: O "mistério da Cidade dos Gêmeos" sendo notícia na imprensa brasileira e internacional.

\begin{tabular}{|c|c|c|}
\hline Título da matéria & Ano & Fonte \\
\hline \multicolumn{3}{|l|}{ Imprensa nacional } \\
\hline Livro conta refúgio nazista na Argentina & 1995 & Folha de São Paulo ${ }^{12}$ \\
\hline Livro atribui a Mengele 'boom' de gêmeos em cidade gaúcha & 2009 & BBC Brasil ${ }^{13}$ \\
\hline Nazista Josef Mengele criou "cidade dos gêmeos" no Rio Grande do Sul & 2009 & Época ${ }^{14}$ \\
\hline Cidade gaúcha recusa título de 'terra dos gêmeos de Mengele' & 2009 & $\mathrm{G} 1^{15}$ \\
\hline Livro gera polêmica na "cidade dos gêmeos" & 2009 & Estadão ${ }^{16}$ \\
\hline O Anjo da Morte e os gémeos de Cândido Godói, no Brasil & 2010 & Público ${ }^{17}$ \\
\hline O fim do mistério & 2011 & Folha de São Paulo ${ }^{18}$ \\
\hline Gene pode explicar mistério da "cidade dos gêmeos" no Rio Grande do Sul, diz estudo & 2011 & $\mathrm{UOL}^{19}$ \\
\hline Gene explica elevada taxa de gêmeos no RS & 2011 & Estadão 20 \\
\hline $\begin{array}{l}\text { Conheça Cândido Godói (RS), a cidade dos gêmeos } \\
\text { Imprensa Internacional }\end{array}$ & Imprensa Internacional & $\mathrm{R} 7^{21}$ \\
\hline Nazi angel of death Josef Mengele 'created twin town in Brazil' & 2009 & The New York Times 22 \\
\hline Mystery of the 'Land of Twins': Something in the Water? Mengele? & 2009 & The Telegraph ${ }^{23}$ \\
\hline "Nazi Twins" a Myth: Mengele Not Behind Brazil Boom? & 2009 & National Geographic ${ }^{24}$ \\
\hline Nature or sinister design: what's going on in town with highest rate of twins? & 2009 & The Guardian 25 \\
\hline In a Brazilian Town, a Rogue Gene and a Boom in Twins & 2011 & The New York Times ${ }^{26}$ \\
\hline Inside the Brazilian town known as 'Twin Land' & 2014 & Mail Online ${ }^{27}$ \\
\hline El fascinante misterio del pueblo con más gemelos del mundo & 2015 & BBC Mundo 28 \\
\hline Inside the Nazi clone village: 'Hitler's fugitive genius' bizarre blue-eyed, blond twins' & 2016 & Daily Star $^{29}$ \\
\hline
\end{tabular}

Todas as fontes foram acessadas em Agosto de 2018. 
O ano de 2008 também é o ano de criação do Instituto Nacional de Ciência e Tecnologia de Genética Médica Populacional (INaGeMP) ${ }^{3}$. Assim, considerando o ressurgimento das polêmicas envolvendo a comunidade e o avanço dos conhecimentos e possibilidades metodológicas, o grupo de investigadores decide retornar a CG e prosseguir a investigação.

Mais de dez anos depois do primeiro contato, a comunidade local também estava diferente, muito mais orgulhosa do título de "Cidade dos Gêmeos". Observa-se na cidade um pórtico anunciando a entrada na "Terra dos Gêmeos", o "Museu dos Gêmeos" e várias placas com um símbolo com duas faces, representando os gêmeos (Figura 1). A cada dois anos realiza-se a "Festa dos Gêmeos" na linha São Pedro. Além disso, uma explicação local para a alta taxa gemelar surgiu: a água de uma fonte local.

\section{PLANEJANDO O PROJETO: ASPECTOS ÉTICOS, COMUNICAÇÃO COM A COMUNIDADE E TIME MULTIDISCIPLINAR}

Todas as visitas a CG foram planejadas com a ajuda de colaboradores locais com reuniões entre os pesquisadores, famílias de gêmeos e demais residentes da cidade. Essas reuniões foram realizadas em espaços públicos, como o Centro de Tradições Gaúchas (onde as pessoas se reúnem para celebrar a cultura gaúcha), a igreja católica e a rádio local. Nestes encontros, foi explicado como o projeto seria realizado, detalhando a metodologia e princípios de genética em uma linguagem tão acessível quanto possível.

Sob coordenação de Ursula Matte (HCPA bióloga que visitou a comunidade em 1994) e Lavínia Schuler-Faccini (SGM-HCPA/INaGeMP), foi composta

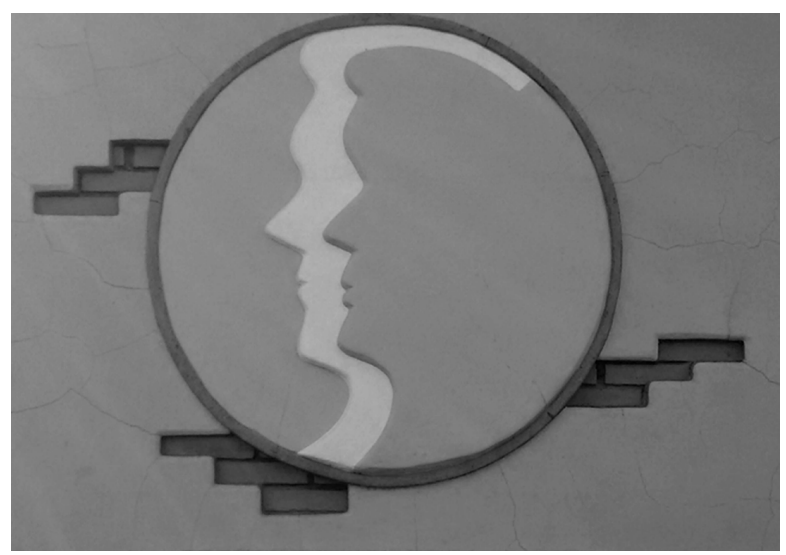

Figura 1: Uma das muitas placas espalhadas pela cidade de Cândido Godói mostrando uma face dupla simbolizando os gêmeos. uma equipe multiprofissional para re-investigar os nascimentos gemelares em CG considerando três frentes principais: genética, ambiente e história do município. Esta equipe foi composta por geneticistas, geólogos, historiador, cientista social e facilitadores (estes dois últimos eram representados por moradores da própria comunidade).

\section{HIPÓTESES, ESTRATÉGIAS CIENTÍFICAS E PRINCIPAIS RESULTADOS}

Imediatamente, para testar a "hipótese do Mengele", foi realizado um estudo epidemiológico utilizando os registros de batismo da igreja católica local (visto que a maioria dos habitantes é católica), pois de acordo com essa teoria, os nascimentos gemelares em CG só teriam aumentado após a hipotética chegada do médico nazista à região (entre 1964 e 1968). Este foi o primeiro trabalho publicado, onde foram analisados mais de 6000 registros de batismo entre 1927 e 2008, identificando-se 91 pares de gêmeos e 1 caso de trigêmeos. Este estudo mostrou que a frequência de nascimentos gemelares era semelhante antes década de 1960 (quando supostamente Mengele teria residido na região) e posteriormente. O que acontece nas décadas de 1960 e 1970 é um aumento no número total de nascimentos e por consequência, os número absoluto de nascimentos gemelares também aumenta ${ }^{30}$.

Os pesquisadores postularam portanto, uma hipótese baseada na premissa multifatorial da gemelaridade onde os nascimentos gemelares em CG seriam o resultado da concentração de alelos de predisposição em algumas famílias devido ao efeito genético do fundador associado com o isolamento reprodutivo ${ }^{31,32}$. O efeito fundador ocorre quando uma nova população é formada a partir de uma amostra não representativa da população inicial. Neste caso, um fator genético (ou mais de um) que predisponha ao nascimento de gêmeos e que é raro em uma população maior, adquire uma frequência mais alta em uma população derivada desta primeira apenas porque uma proporção exagerada de indivíduos com esta característica estava entre os poucos fundadores da nova população ${ }^{33}$. O isolamento reprodutivo, ou seja, o fato de que os casamentos são realizados quase que exclusivamente entre os membros da mesma população contribui ainda mais para que um fator genético aumente ainda mais de frequência ${ }^{34}$.

Para testar essa hipótese com profundidade, trabalhou-se diretamente com a comunidade, através de questionário detalhado às famílias envolvidas, focando na presença de gêmeos em gerações passadas, medidas antropométricas, informações gestacionais e hábitos alimentares. Elaborou-se 
um estudo caso-controle com mães residentes em CG, onde o grupo de casos foi formado por mães de gêmeos e o grupo de controles por mães de únicos que não apresentassem um histórico de gemelaridade em parentes de primeiro grau. Amostras de sangue e/ou saliva foram coletadas para a realização dos testes genéticos.

No laboratório, procurou-se no material genético das mães de CG variações em genes que já tinham sido relacionados à reprodução humana na literatura científica. Com esta abordagem, foi encontrada uma frequência estaticamente maior do alelo P72 do gene TP53 em mães de gêmeos quando comparada com mães de não-gêmeos ${ }^{35}$. O produto deste gene é um importante supressor tumoral que está envolvido em uma ampla variedade de processos biológicos, como desenvolvimento, imunidade, envelhecimento, câncer e a reprodução ${ }^{35-39}$. Especificamente no campo da fertilidade, foi demonstrado que o papel regulador do gene TP53 é importante tanto no processo de implantação do blastocisto na parede uterina quanto após, de modo que as chances de uma concepção gemelar suceder-se a termo podem ser aumentadas em mulheres que carreiam o alelo $\mathrm{P} 72^{30}$.

Além de apoiar a hipótese previamente formulada para o mistério em CG, este foi o primeiro estudo a associar a via $\mathrm{p} 53 \mathrm{com}$ a gemelaridade em humanos e este achado tem sido replicado por outros trabalhos envolvendo outras populações ${ }^{40,41}$. Recentemente, continuamos testando algumas outras variantes genéticas relacionadas à reprodução humana, mas os resultados não parecem indicar alguma influência dos candidatos investigados com o fenômeno ${ }^{42,43}$.

Variáveis ambientais também foram testadas: solo e água quanto à presença de pesticidas (desreguladores endócrinos) e metais pesados. Não encontramos nenhum resultado anormal na análise de água e solo que pudesse ajudar a explicar a alta taxa gemelar na região de CG.
Em outro trabalho, foram estudados os sobrenomes de todos os residentes em CG como um indicador de tipos de casamentos e também localizamos geograficamente todas as residências onde os gêmeos nasceram. Deste modo, encontramos altos índices de endogamia junto com baixa dispersão populacional especialmente na LSP, onde sabidamente registravam-se maiores taxas de gemelaridade ${ }^{44}$.

\section{TRABALHANDO COM A COMUNIDADE: CONTRIBUIÇÕES AO MUNICÍPIO}

Um dos principais produtos deste trabalho foi a construção detalhada de árvores genealógicas das famílias com gêmeos (heredogramas). Um exemplo está apresentado na Figura 2.

Antes de serem publicados, os principais achados dos nossos trabalhos foram apresentados e discutidos com a população no salão paroquial da igreja católica local. Na ocasião, imprimimos os heredogramas das famílias participantes e deixamos à disposição da comunidade.

No processo de trabalho em nosso projeto, alguns produtos foram entregues ao município de CG. Um marco de geo-localização foi registrado no sistema de satélites (DNA1), permitindo um posicionamento mais acurado na região. Mapas com localização precisa de escolas, instalações de água e igrejas, também foram disponibilizados através de instrumentos do Sistema de Informação Geográfica (SIG) e entregues ao município. Mapas anteriores ainda eram desenhados manualmente com tinta no papel. Um computador com os pedigrees também foi doado ao município.

\section{INTERAÇÃO COM A MÍDIA}

Desde o primeiro contato na década de 1990, o mistério dos gêmeos em CG tem recebido uma notável atenção midiática (Tabela 1). A mídia não estava apenas se aproximando de nós para entrevistas

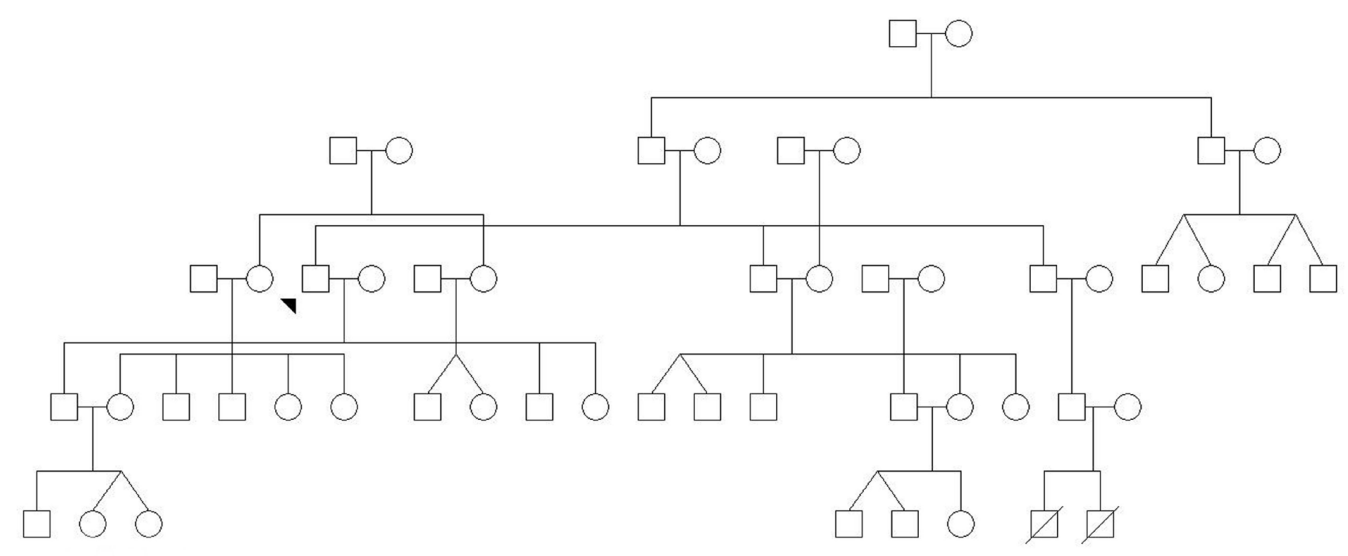

Figura 2: Heredograma de uma família de Cândido Godói. 
e documentários, mas também estava em contato com a própria comunidade.

Nós tentamos adotar uma política de neutralidade, comentando apenas os resultados já publicados. Qualquer pedido que envolvesse entrar em contato com a comunidade deveria ser autorizado diretamente por eles. Não serviríamos como facilitadores para qualquer pessoa que desejasse alcançar a comunidade para outros fins que não a investigação científica. Mesmo naqueles casos em que compreendíamos que a interação com a mídia seria positiva para toda a comunidade, deixamos claro que a decisão seria deles. Era importante que não apenas tivéssemos essa atitude, mas que isso fosse percebido e compreendido pela comunidade.

\section{DISCUSSÃO: A GEMELARIDADE DENTRO E FORA DE CG}

As taxas de nascimentos gemelares variam muito ao redor do mundo, sendo consideradas mais frequentes em populações sub-saarianas (até 27 por 1000 nascimentos em alguns países), intermediárias em populações norte-americanas e europeias (9-16 por 1000 nascimentos) e menos freqüentes em populações asiáticas e sul-americanas (6-9 por 1000 nascimentos) $)^{45,46}$. No Brasil, mostramos recentemente que a cada 1000 nascimentos registrados, aproximadamente 9,4 são gemelares ${ }^{47}$. Neste mesmo estudo, observamos também que existe uma tendência ascendente nas taxas de gemelaridade apenas para algumas áreas do país (principalmente, naqueles lugares com um alto IDH) e que é ainda mais pronunciada em algumas mulheres, sobretudo aquelas de idade mais avançada.

As diferenças nas taxas de gemelaridade entre os países foram geralmente consideradas apenas devido à variação na gemelaridade dizigótica, uma vez que a epidemiologia dos gêmeos monozigóticos permaneceu constante em todo o mundo (aproximadamente 4 por 1000) ) $^{31,48}$. No entanto, recentemente foi demonstrado que os fatores ambientais ligados à reprodução medicamente assistida podem influenciar as taxas de gêmeos $M Z^{49,50}$.

A gemelaridade é atualmente compreendida como uma característica humana multifatorial ${ }^{31,51}$. Fatores ambientais, como a maternidade tardia e tratamentos ligados à reprodução medicamente assistida têm sido apontados como as principais causas para o aumento geral das taxas de gemelaridade em todo o mundo, inclusive no Brasil 46,47,50. Outros fatores como aumento da paridade, lactação, dieta, maior altura materna, índice de massa corporal, status socioeconômico, raça e tabagismo são também apontados como fatores de risco para a gemelaridade dizigótica ${ }^{41,50,52,53}$.

Interessantemente, os principais fatores ambientais ligados ao nascimento de gêmeos no mundo contemporâneo não parecem exercer grande influência em CG, bem como em algumas outras poucas cidades ao redor do mundo onde 0 fenômeno das altas taxas gemelares é observado ${ }^{41,54-56}$. Somam-se a isto as diferenças étnicas naturalmente encontradas para as taxas gemelares, bem como uma alta predisposição intrafamiliar para gemelaridade já relatada na literatura ${ }^{52,54}$. Em conjunto, estes achados reforçam a participação de fatores genéticos na gemelaridade, muito embora apenas poucos genes tenham sido identificados e implicados na etiologia dos nascimentos gemelares ${ }^{35,57-61}$.

De fato, a etiologia dos nascimentos gemelares na espécie humana ainda é muito pouco compreendida e tem sido sujeito de investigação ao redor do mundo através de diferentes abordagens. O estudo de populações com altas taxas gemelares ocorrendo naturalmente pode contribuir com a caracterização de quais fatores biológicos podem estar associados com a gemelaridade, como mostrado aqui.

Os estudos em CG têm contribuído não apenas com a resolução de um mistério local, mas também com as bases biológicas da gemelaridade humana e com o campo da reprodução, de maneira geral. Além disso, acreditamos que os principais resultados deste trabalho podem ter contribuído com o empoderamento de toda aquela especial comunidade. Neste tipo de trabalho somos colocados à frente de uma série de desafios que envolvem toda uma comunidade, os quais vão desde aspectos éticos específicos durante a concepção do projeto até a tradução da linguagem científica para termos acessíveis a pessoas não-cientistas, as quais eram, de fato, as principais interessadas no assunto.

\section{Agradecimentos}

Agradecemos a todos os membros do município de Cândido Godói que foram muito prestativos e acolhedores durante todo o desenvolvimento do projeto. Também fazemos agradecimentos especiais àqueles que nos auxiliaram no contato com as famílias e no entendimento de questões históricas.

\section{Conflitos de Interesse}

Os autores declaram não ter conflitos de interesse. 


\section{REFERÊNCIAS}

1. Castilla EE. On being a medical geneticist. Am J Med Genet. 2005;138A(3):197-8.

2. Poletta FA, Orioli IM, Castilla EE. Genealogical data in population medical genetics: field guidelines. Genet Mol Biol. 2014;37(1 Suppl 1):171-85. http://dx.doi.org/10.1590/ S1415-47572014000200004. PMid:24764752.

3. Giugliani R, Bender F, Couto R, Bochernitsan A, Brusius-Facchin AC, Burin $\mathrm{M}$, et al. Population medical genetics: translating science to the community. Genet Mol Biol. 2019. http://dx.doi.org/10.1590/1678-4685gmb-2018-0096. PMid:30985854.

4. Instituto Brasileiro de Geografia e Estatística (IBGE). Censo demográfico 2010. 2010. [citado 2017 Abr 14]. Disponível em: http://www.ibge. gov.br/home/estatistica/populacao/ censo2010/

5. Brasil. Ministério da Saúde. Departamento de Informática do SUS - DATASUS. [citado 2018 Ago 14]. Disponível em: http://www.bbc. com/mundo/noticias/2015/10/151009_ salud_gemelos_brasil_lb

6. Matte U, Le Roux MG, Bénichou B, Moisan JP, Giugliani R. Study on possible increase in twinning rate at a small village in south Brazil. Acta Genet Med Gemellol. 1996;45(4):4317. http://dx.doi.org/10.1017/ S0001566000000829. PMid:9181177.

7. Camarasa J. Josef Mengele: o anjo da morte na America do Sul. Buenos Aires Grupo Editorial NORMA; 2008. $188 \mathrm{p}$.

8. Camarasa J. Odessa al sur: la Argentina como refugio de Nazis y criminals de Guerra. Buenos Aires: Editorial Planeta; 1995. 345 p.

9. Amstad T. Cem anos de germanidade no Rio Grande do Sul (1824-1924). Rambo AB, tradutor. São Leopoldo: Editora Unisinos; 1999. 646 p.

10. Rückert FQ. A colonização alemã e italiana no Rio Grande do Sul: uma abordagem na perspectiva da História Comparada. Rev Bras História Ciências Sociais. 2013;5(10):203-25.

11. Tedesco JC, Heinsfeld A. Colonos, colônias e colonizadores: aspectos da territorialização agrária no sul do Brasil. Erechim: Habilis; 2009. 262 p.
12. Folha de São Paulo. [citado 2018 Ago 14]. Disponível em: http://www1.folha. uol.com.br/fsp/1995/9/24/mundo/12. html

13. Brasil BBC. [citado 2018 Ago 14]. Disponível em: http://www.bbc.com/ portuguese/noticias/2009/01/090123 mengelegemeosrw_tc2

14. Época. [citado 2018 Ago

14]. Disponível em: http:// revistaepoca.globo.com/Revista/ Epoca/0,EMI24803-15228,00-NAZIST A+JOSEF+MENGELE+CRIOU+CIDA $\mathrm{DE}+\mathrm{DOS}+\mathrm{GEMEOS}+\mathrm{BRNO}+\mathrm{RIO}+\mathrm{GR}$ ANDE+DO+SUL+DIZ+LI.html

15. G1. [citado 2018 Ago 14]. Disponível em: http://g1.globo.com/Noticias/ Brasil/0,MUL995232-5598,00-CIDADE +GAUCHA+RECUSA+TITULO+DE+T ERRA+DOS+GEMEOS+DE+MENGE LE.html

16. Estadão. [citado 2018 Ago 14]. Disponível em: http://emais. estadao.com.br/noticias/geral,livrogera-polemica-na-cidade-dosgemeos, 316223

17. Público. [citado 2018 Ago 14]. Disponível em: https://www.publico. pt/2010/05/29/jornal/o-anjo-da-mortee-os-gemeos-de-candido-godoi-nobrasil-19503571

18. Folha de São Paulo. [citado 2018 Ago 14]. Disponível em: http://www1.folha. uol.com.br/fsp/ciencia/fe2603201101. htm

19. UOL. [citado 2018 Ago 14]. Disponível em: https://noticias.uol.com.br/ cotidiano/ultimas-noticias/2011/03/25/ gene-pode-explicar-misterio-dacidade-dos-gemeos-no-rio-grande-dosul-mostra-estudo.htm

20. Estadão. [citado 2018 Ago 14]. Disponível em: http://www.estadao. com.br/noticias/geral,gene-explicaelevada-taxa-de-gemeos-no-rsimp-,697498

21. R7. [citado 2018 Ago 14]. Disponível em: http://tv.r7.com/record-play/tudoa-ver/videos/conheca-candido-godoirs-a-cidade-dos-gemeos-21102015

22. The New York Times. [citado 2018 Ago 14]. Disponível em: http://www. nytimes.com/2009/02/23/world/ americas/23twins.html
23. The Telegraph. [citado 2018 Ago 14]. Disponível em: http://www.telegraph. co.uk/news/worldnews/southamerica/ brazil/4307262/Nazi-angel-of-deathJosef-Mengele-created-twin-town-inBrazil.html

24. National Geographic. [citado 2018 Ago 14]. Disponível em: https:// news.nationalgeographic.com/ news/2009/11/091125-nazi-twinsbrazil-mengele.html

25. The Guardian. [citado 2018 Ago 14]. Disponível em: https://www. theguardian.com/world/2009/dec/11/ twins-brazil-mengele-theory

26. The New York Times. [citado 2018 Ago 14]. Disponível em: http://www. nytimes.com/2011/03/25/world/ americas/25brazil.html

27. Mail Online. [citado 2018 Ago 14]. Disponível em: http://www.dailymail. co.uk/news/article-2604223/InsideBrazils-Twin-Land-C-ndido-God-Naziexperiment.html

28. BBC Mundo. [citado 2018 Ago 14]. Disponível em: http://www.bbc.com/ mundo/noticias/2015/10/151009_ salud_gemelos_brasil_lb

29. Daily Star. [citado 2018 Ago 14]. Disponível em: https://www.dailystar. co.uk/news/latest-news/541289/ national-socialist-genetic-geniusjosef-mengele-candido-godoi-jorgecamarasa

30. Tagliani-Ribeiro A, Oliveira M, Sassi AK, Rodrigues MR, Zagonel-Oliveira $M$, Steinman $G$, et al. Twin town in south Brazil: a Nazi's experiment or a genetic founder effect? PLoS One. 2011;6(6):e20328.

31. Hall JG. Twinning. Lancet. 2003;362(9385):735-43. http://dx.doi. org/10.1016/S0140-6736(03)14237-7. PMid:12957099.

32. Shur N. The genetics of twinning: from splitting eggs to breaking paradigms. Am J Med Genet C Semin Med Genet. 2009;151C(2):105-9. http:// dx.doi.org/10.1002/ajmg.c.30204. PMid:19363800.

33. Zlotogora J. Multiple mutations responsible for frequent genetic diseases in isolated populations. Eur $J$ Hum Genet. 2007;15(3):272-8. http:// dx.doi.org/10.1038/sj.ejhg.5201760. PMid:17213840. 
34. Schüler-Faccini L, Giugliani R. Population medical genetics in Brazil. In: Kumar D, editor. Genomics and health in the developing world. New York: Oxford University Press; 2012. p. 1231-6.

35. Tagliani-Ribeiro A, Paskulin DD, Oliveira M, Zagonel-Oliveira M, Longo D, Ramallo V, et al. High twinning rate in Cândido Godói: a new role for p53 in human fertility. Hum Reprod. 2012;27(9):2866-71. http:// dx.doi.org/10.1093/humrep/des217. PMid:22736329.

36. Bianco B, Christofolini DM, Brandes A, Lerner TG, Gonçalves-Filho RP, Souza AMB, et al. Análise do polimorfismo no códon 72 do gene TP53 em mulheres inférteis com e sem endometriose. Rev Bras Ginecol Obstet. 2011;33(1):3742. http://dx.doi.org/10.1590/ S0100-72032011000100006. PMid:21625792.

37. Bieging KT, Mello SS, Attardi LD Unravelling mechanisms of $p 53-$ mediated tumour suppression. Nat Rev Cancer. 2014;14(5):359-70. http://dx.doi.org/10.1038/nrc3711. PMid:24739573.

38. Instituto Brasileiro de Geografia e Estatística (IBGE). Atlas do Desenvolvimento Humano no Brasil. Índice de desenvolvimento humano municipal brasileiro. 2013. 97 p.

39. Hu W, Feng Z, Teresky AK, Levine AJ. p53 regulates maternal reproduction through LIF. Nature. 2007;450(7170):721-4. http:// dx.doi.org/10.1038/nature05993. PMid:18046411.

40. Mardini AC, Pereira FS, SchulerFaccini L, Matte U. Analysis of polymorphism rs 1042522 in TP53 gene in the mothers of twins and of singletons: a population-based study in Rio Grande do Sul, Brazil. Twin Res Hum Genet. 2017;20(2):132-6. http://dx.doi.org/10.1017/thg.2017.2. PMid:28179045.

41. Huang $\mathrm{H}$, Clancy KBH, Burhance C, Zhu Y, Madrigal L. Women who deliver twins are more likely to smoke and have high frequencies of specific SNPs: results from a sample of African-American women who delivered preterm, low birth weight babies. Am J Hum Biol. 2015;27(5):605-12. http:// dx.doi.org/10.1002/ajhb.22723. PMid:25882505.
42. Oliveira-Klein M, Cardoso-dosSantos AC, Tagliani-Ribeiro A, Fagundes NR, Matte U, SchulerFaccini L. Lack of association between genetic polymorphisms in IGF1 and IGFBP3 with twin births in a Brazilian population (Cândido Godói, Rio Grande do Sul). Genet Mol Biol. 2018;41(4):775-80. http:// dx.doi.org/10.1590/1678-4685gmb-2017-0263. PMid:30508002.

43. Cardoso-dos-Santos AC, TaglianiRibeiro A, Matte U, Schuler-Faccini L. Genetic variants linked to folliculogenesis and successful pregnancy are not associated with twin births in a twins' town. J Matern Fetal Neonatal Med. 2019;1-8. http:// dx.doi.org/10.1080/14767058.2019.15 73791. PMid:30843750.

44. Oliveira MZ, Schüler-Faccini L, Demarchi DA, Alfaro EL, Dipierri JE, Veronez MR, et al. So close, so far away: analysis of surnames in a town of twins (Cândido Godói, Brazil). Ann Hum Genet. 2013;77(2):125-36. http://dx.doi.org/10.1111/ahg.12001. PMid:23369099.

45. Smits J, Monden C. Twinning across the developing world. PLoS One. 2011;6(9):e25239.

46. Pison G, Monden C, Smits J. Twinning rates in developed countries: trends and explanations. Popul Dev Rev. 2015;41(4):629-49. http://dx.doi.org/10.1111/j.17284457.2015.00088.x.

47. Cardoso-dos-Santos AC, Boquett J, Oliveira MZ, Callegari-Jacques SM, Barbian MH, Sanseverino MTV, et al. Twin Peaks: a spatial and temporal study of twinning rates in Brazil. PLoS One. 2018;13(7):e0200885. http://dx.doi.org/10.1371/journal. pone.0200885. PMid:30028857.

48. Hoekstra C, Zhao ZZ, Lambalk CB, Willemsen G, Martin NG, Boomsma DI, et al. Dizygotic twinning. Hum Reprod Update. 2008;14(1):37-47. http://dx.doi.org/10.1093/humupd/ dmm036. PMid:18024802.

49. Sobek A, Prochazka M, Klaskova E, Lubusky M, Pilka R. High incidence of monozygotic twinning in infertility treatment. Biomed Pap. 2016;160(3):358-62.

50. Dawson AL, Tinker SC, Jamieson DJ, Hobbs CA, Berry RJ, Rasmussen $\mathrm{SA}$, et al. Twinning and major birth defects, national birth defects prevention study, 1997-2007. J Epidemiol Community Health. 2016;70(11):1114-21. http://dx.doi. org/10.1136/jech-2015-206302. PMid:27325867.

51. McNamara HC, Kane SC, Craig JM, Short RV, Umstad MP. A review of the mechanisms and evidence for typical and atypical twinning. Am J Obstet Gynecol. 2016;214(2):172-91. http:// dx.doi.org/10.1016/j.ajog.2015.10.930. PMid:26548710.

52. Hoekstra C, Willemsen G, van Beijsterveldt TCEM, Montgomery GW, Boomsma DI. Familial twinning and fertility in Dutch mothers of twins. Am J Med Genet A. 2008;146A(24):314756. http://dx.doi.org/10.1002/ ajmg.a.32585. PMid:19012341.

53. Steinman G. Can the chance of having twins be modified by diet? Lancet. 2006;367(9521):1461-2. http://dx.doi. org/10.1016/S0140-6736(06)68623-6. PMid:16679141.

54. Hamamy HA, Ajlouni HK, Ajlouni KM. Familial monozygotic twinning: report of an extended multi-generation family. Twin Res. 2004;7(3):219-22. http://dx.doi. org/10.1375/136905204774200479. PMid:15193164.

55. Sunde J, Boric M, Urlic N, Urlic L. Comparison of twinning rates for villages in Makarska region, Croatia. J Biosoc Sci. 2013;45(6):841-52. http://dx.doi. org/10.1017/S0021932013000011. PMid:23410510.

56. Sahab Khan P, Skandhan KP. Kodinji village puzzles medical science. $J$ Obstet Gynaecol Res. 2011;37(4):3756. http://dx.doi.org/10.1111/j.14470756.2010.01455.x. PMid:21349133.

57. Palmer JS, Zhao ZZ, Hoekstra C, Hayward NK, Webb PM, Whiteman DC, et al. Novel Variants in growth differentiation factor 9 in mothers of dizygotic twins. J Clin Endocrinol Metab. 2006;91(11):4713-6. http:// dx.doi.org/10.1210/jc.2006-0970. PMid:16954162.

58. Mbarek H, Steinberg S, Nyholt DR, Gordon SD, Miller MB, McRae $A F$, et al. Identification of common genetic variants influencing spontaneous dizygotic twinning and female fertility. Am J Hum Genet. 2016;98(5):898-908. http://dx.doi. org/10.1016/j.ajhg.2016.03.008. PMid:27132594. 
59. Painter JN, Willemsen G, Nyholt D, Hoekstra C, Duffy DL, Henders $A K$, et al. A genome wide linkage scan for dizygotic twinning in $\mathbf{5 2 5}$ families of mothers of dizygotic twins. Hum Reprod. 2010;25(6):1569-80. http:// dx.doi.org/10.1093/humrep/deq084 . PMid:20378614.
60. Al-Hendy A, Moshynska O, Saxena A, Feyles V. Association between mutations of the folliclestimulating-hormone receptor and repeated twinning. Lancet. 2000;356(9233):914. http://dx.doi. org/10.1016/S0140-6736(00)02687-8. PMid:11036902.
61. Hasbargen $U$, Lohse $P$, Thaler CJ. The number of dichorionic twin pregnancies is reduced by the common MTHFR $677 \mathrm{C} \rightarrow \mathrm{T}$ mutation. Hum Reprod.

2000;15(12):2659-62. http://dx.doi. org/10.1093/humrep/15.12.2659.

PMid:11098041.

Recebido: 16 jun, 2019

Aceito: 18 jun, 2019 